\title{
Leonidas Proaño: orientación periodística más allá de lo religioso y educativo
}

\section{Leonidas Proaño: journalistic orientation beyond the religious and educational}

\section{Leonidas Proaño: orientação jornalística além do religioso e educacional}

\author{
Julio Bravo Mancero ${ }^{1}$ \\ Universidad Nacional de Chimborazo (Ecuador) \\ jbravo@unach.edu.ec \\ Fermín Galindo Arranz ${ }^{2}$ \\ Universidad Santiago de Compostela (España) \\ fermin.galindo@usc.es \\ Susana Bravo Mancero ${ }^{3}$ \\ Escuela Superior Politécnica de Chimborazo (Ecuador) \\ susanabravom@hotmail.com
}

Fecha de recepción: 20 de abril de 2019

Fecha de recepción evaluador: 25 de abril de 2019

Fecha de recepción corrección: 15 de mayo de 2019

\footnotetext{
${ }^{1}$ Julio Bravo Mancero. Doctor en Comunicación e Información Contemporánea de la Universidad Santiago de Compostela. https://orcid.org/0000-0002-4468-9247

${ }^{2}$ Fermín Galindo Arranz. Doctor en Ciencias de la Información por la Universidad del País Vasco (1992) y Profesor Titular de Periodismo de la Universidad de Santiago de Compostela. https://orcid.org/00000002-2764-2121

${ }^{3}$ Susana Bravo Mancero. Magister en Marketing de la Escuela Superior Politécnica de Chimborazo; Ingeniera de Empresas de la Espoch; docente de la especialización de Marketing; ha sido Asistente de Cuentas Corrientes, Jefe Operativo y Asesor de Negocios, Banco Internacional; Oficial de Instrumentación 2. https://orcid.org/0000-0003-2992-9262
} 


\title{
Resumen
}

Este artículo investiga y comprueba cómo la orientación de los medios de comunicación masiva fundados por Leonidas Proaño dirigió sus propuestas periodísticas no solo desde lo religioso - educativo, como se ha argumentado, sino que utilizó lo social, político, sindical, acción y desarrollo para relatar la vida en las comunidades indígenas y barrios urbano marginales del Ecuador en procurar de la transformación; evidencia su faceta como periodista En el trabajo se empleó metodología de tipo mixta: cualitativa y cuantitativa, a través del análisis y la revisión documental de la información y opinión contenidas en las páginas de los impresos (Excélsior, Ganitas de Trigo, El Cuadrilátero, Mensaje, Jatari Campesino y Jatari) y en los guiones de los programas radiofónicos emitidos por ERPE y Promoción, entre 1934 y 1984. Se recuperaron, analizaron e interpretaron 366 documentos publicados-emitidos. Las observaciones fueron teorizadas utilizando criterios de especialistas en comunicación, periodismo, sociología y medios masivos publicados en libros y revistas indexadas que reposan en bases de datos internacionales. Los resultados advirtieron la cercanía del religioso con el periodismo, el adecuado manejo de las formas de presentación de las historias en la media y los actos de comunicación en los que obtuvo información para convertirla en contenidos.

Palabras clave: comunicación; periodismo; orientación; géneros y formatos; cambio social; indígenas.

\begin{abstract}
This article investigates and verifies how the orientation of the mass media founded by Leonidas Proaño directed their journalistic proposals not only from the religious [ educational, as has been argued, but used the social, political, trade union, action and development to relate life in the indigenous communities and slums of Ecuador and to seek transformation; its facet as a journalist is also evident. Mixed methodology was used: qualitative and quantitative, through the analysis and documentary review of the information and opinion contained in the pages of the forms (Excélsior, Ganitas de Trigo, El Cuadrilaero, Mensaje, Jatari Campesino and Jatari) and in the scripts of the radio programmes broadcast by ERPE and Promoción, between 1934 and 1984. 366 publishedissued documents were recovered, analysed and interpreted. The observations were theorized using criteria of specialists in communication, journalism, sociology and mass media published in indexed books and journals based on international databases. The results indicated a prolific closeness with journalism, the proper handling of the forms of presentation of stories in the media and the acts of communication in which he obtained information to convert it into content.
\end{abstract}

Keywords: communication; journalism; orientation; gender and formats; social change; indigenous 


\section{Resumo}

Este artigo investiga e verifica como a orientação da mídia de massa fundada por Leonidas Proaño direcionou suas propostas jornalísticas não apenas dos religiosos [educacionais, como foi discutido, mas usaram o social, político, sindical, ação e desenvolvimento para relacionar a vida em comunidades indígenas e favelas do Equador e buscar transformação; sua faceta como jornalista também é evidente. Utilizou-se metodologia mista: qualitativa e quantitativa, através da análise e revisão documental das informações e opiniões contidas nas páginas dos formulários (Excélsior, Ganitas de Trigo, El Cuadrilaero, Mensaje, Jatari Campesino e Jatari) e nos roteiros do programas de rádio transmitidos pela ERPE e Promoción, entre 1934 e 1984. 366 documentos publicados foram recuperados, analisados e interpretados. As observações foram teorizadas usando critérios de especialistas em comunicação, jornalismo, sociologia e mídia de massa publicados em livros e revistas indexados com base em bancos de dados internacionais. Os resultados indicaram uma proximidade prolífica com o jornalismo, o manejo adequado das formas de apresentação de matérias na mídia e os atos de comunicação nos quais ele obteve informações para convertê-las em conteúdo.

Palavras-chave: comunicação; jornalismo; orientação; gênero e formatos; mudança social; indígena

\section{Introducción}

Este manuscrito aborda la orientación de los medios masivos fundados por Leonidas Proaño, durante 50 años, en tres etapas definidas de su vida: seminarista, sacerdote y Obispo de la Diócesis de Riobamba; el empleo de géneros y formatos de opinión e información que hicieron visibles los problemas de opresión, marginación y esclavitud de los indígenas ubicados en el campo y de los mestizos que habitaban en los sectores urbano-marginales de las ciudades; y los actos comunicativos (escucha, diálogo y difusión) para acumular datos y difundirlos en los media. Estos tres aspectos que motivaron esta investigación que se desprende del proceso de formación doctoral en la Universidad Santiago de Compostela, identificaron su lucha por la transformación de la gente empobrecida.

Se utilizó como pregunta de investigación ¿Cuál fue la orientación de los medios fundados por Proaño y el reflejo en la difusión de la realidad socio-cultural y la actitud de cambio social de las comunidades indígenas de Ecuador entre 1934 y 1984? Se propuso como objetivo: Identificar el posicionamiento de los medios, la difusión de la pobreza del indio y la búsqueda de la transformación. La metodología fue cualitativa y cuantitativa; como técnicas se utilizaron la revisión documental; y el análisis de contenido.

La realidad del indígena es similar en los países de Latinoamérica, sin embargo, para el caso ecuatoriano, en las últimas décadas, se profundizaron estudios sobre aspectos considerados poco trascendentes y sin aportaciones; y también, de la búsqueda de la modificación de las vidas de la gente del campo y la ciudad. Si bien, Saldívar (2003) 
identifica el inicio de la investigación formal sobre este tema, en el 90, existe evidencia del trabajo de Proaño cuatro décadas antes en las provincias de Imbabura y Chimborazo, como se visibilizará en la discusión de resultados.

Taita Proaño coincide con Ramón Máiz (2004, p. 130) quien señala "la emergencia de las movilizaciones indigenistas en América Latina como un fenómeno político de primera magnitud" evidente a través de largos procesos de mentalización, toma de conciencia y de cambio de actitud; La organización y agrupamiento de los indígenas permitió pasar de lo individual a lo colectivo en Ecuador; Ortiz (20011, p. 68) sostiene que "la lucha del movimiento indígena se desarrolla en el marco de la recuperación o reafirmación de sus identidades".

Los resultados de la investigación identifican que los medios de Proaño orientaron sus contenidos desde la religión, educación, política y social. Y que, él se desarrolló como un periodista prolijo que contaba la realidad de los pueblos y sus habitantes usando información y opinión, siempre en procura del cambio social.

La fundamentación teórica considera los aportes de Baudrillard (1984), Canaval (2000); Dubravcic (2002); García (2008); Marcuse (1992); Galeano (1971); Herrera (1992); Igartúa \& Humanes (2010); Kaplún (1983); Lewin (1940); Marcuse (1973); Muñoz (2011); Ossandon (1988); Proaño (1974); Rizo (2012); Serrano (1982); Rojas (2012), entre otros.

\section{Marco Teórico}

\section{Proaño: contexto histórico y social}

Leonidas Proaño nació en San Antonio de Ibarra, en1910. Se ordenó como sacerdote en 1934 después de formarse en los seminarios Menor San Diego (Ibarra) y Mayor (Quito); el Papa Pablo VI lo designó en 1954 Obispo de la Diócesis de Bolívar que luego se llamaría de Riobamba; Luego de 30 años de servicio se jubiló y fue posesionado como Presidente de la Pastoral Indígena de Ecuador (1985) Por su condición se acercó a los pobres con quienes se identificaba.

Proaño (2001) decía que los indígenas viven en situación de marginación; no solamente su acceso a las instituciones sociales y económicas, de desarrollo y bienestar, era menor, sino cuando formalmente llegan a ellos los resultados fueron distintos a los que esperaban. Y esto reflejaba los procesos de dominación. Para (Singer, 2001) dominar es restringir el acceso a los recursos materiales, a la educación y a la cultura. Desemboca en la exclusión y en el abandono.

Ecuador, en el tiempo en que Proaño era seminarista y sacerdote estaba caracterizado por la ruralidad y por la situación de explotación en las grandes haciendas. Los dueños de la tierra tenían el control de los indios que eran considerados inferiores a los animales. La población se concentraba fuera de las ciudades. Un informe de las Naciones Unidas (1954, p. 14). señala que "El 78\% vivía en el campo y la concentración 
urbana solo se daba en Guayaquil y Quito", Los indígenas parecían ser de propiedad de los hacendados quienes controlaban la tierra, sus propiedades, sus familias y hasta su pensamiento; no tenían derecho a elegir y ser elegidos.

En Ibarra, en 1937, organizó la Juventud Obrera Católica (JOC), cuyo génesis estaba en Bruselas en 1912; la entidad dedicada a la formación de los trabajadores había sido fundada por el sacerdote Joseph Cardijn; para conocer la realidad de las personas desarrolló el método de acción católica ver-juzgar-actuar. Sanz (2001) sostiene que la metodología provocaría cambio en el movimiento social católico.

En 1954 cuando asumió el obispado organizó la Visita Pastoral que sirvió para conocer cómo vivía la gente del campo. Se encontró con una situación similar a la de la colonia, como describe Galeano (1971, p. 62). "Los indios debían al encomendero servicios personales y tributos económicos, no era mucho el tiempo que quedaba para introducirlos en el cristiano sendero de la salvación”.

La iglesia católica ecuatoriana formaba parte de la explotación que provocaba la tenencia de la tierra. Una de sus primeras decisiones fue la parcelación de una hacienda diocesana a los integrantes de una cooperativa comunitarias agrícola; este fue el inicio de la reforma agraria en el país. Con la elección de Camilo Ponce como presidente de la República en 1956, miró los resultados en Chimborazo y "promovió la modernización del agro expidiendo en mayo de 1959 la Ley de Reforma Agraria entregando gratuitamente una parte de la tierra a los campesinos" (Proaño, p. 22), con lo que la parcelación se extendió en todo el Ecuador.

\section{La perspectiva comunicacional}

Manuel Martín Serrano (1982, p.18) en la aproximación a la Teoría de la Comunicación coincide con las actuaciones realizadas por Leonidas Proaño, en la definición de la representación de los actos comunicativos como un eje que permite comprender, reflexionar y transformar la realidad; sobre la base de esta propuesta se facilita la comprensión de la forma en la que utilizó la comunicación humana, biológica y tecnológica (prensa y radio). Este hecho permite que los seres vivos "pueden relacionarse con otros seres vivos intercambiando información”. La cercanía del obispo con los indígenas de Ecuador estaba caracterizada por la escucha y asimilación de sus preocupaciones; con el diálogo motivó la mentalización y la toma de conciencia de una problemática que debía intervenirse La comunicación por ser una forma de interacción, supone la participación de los individuos convertidos en actores; es decir otro hecho evidenciable era el paso de simples receptores a actores del cambio. "Los Actores ocupan posiciones distintas y en el transcurso del proceso comunicativo desempeñan funciones diferentes" (Serrano, 19982, p. 19).

Rizo (2012, p. 21) hace énfasis en la interacción social como un instrumento que permite un mejor nivel de comunicación y, encasilla en este nivel a los actos ejercidos por Proaño. La relación con los semejantes debía situarse cogiendo el rol de actor y de protagonista de la transformación. "la función básica de la comunicación humana es 
desarrollar relaciones, más que intercambiar información". Se dejó de lado la unidireccionalidad comunicativa y la reemplazó por la doble vía porque le garantizaba que un "abordaje de la comunicación debe tomar en cuenta esta diversidad de perspectivas y acercamientos", (Rizo, 2018, p. 1).

Proaño se relacionaba con los indios para obtener información; para hacerlo usaba el diálogo, que quizá tenga enfoque subjetivo pero trascendente; este aspecto fue enfocado por Herbert Marcuse en 1929. "El subjetivismo, cuanta postura ontológica, tiene que refugiarse en la cada vez más evanescente concepción abstracta del ser de lo real”, (Muñoz, 2011, p. 3)

En esta temporalidad, la continuidad de la presencia del obispo y las acciones realizadas en las comunidades indígenas de Chimborazo originaron el aparecimiento de la comunicación popular.

"Ante todo, la comunicación popular ya es "un dato" de la realidad. Existe un amplio conglomerado de prácticas de elaboración y/o consumo de mensajes que provienen del pueblo y se dirigen prioritariamente a él. En ocasiones, se dirigen a la sociedad en su conjunto Adquieren formas e intensidades diferentes. según el país o sector en el cual se originan", Ossandon (1988, p. 50)

Dubravcic (2002) la define como una práctica de intercambio cultural y simbólico entre actores con diversidad. Kaplún (1983, p. 40) señala que es una alternativa para el mejoramiento de lo social porque hubo "Carentes de condiciones para enfrentar a las grandes redes masivas, sin peso para incidir en las políticas nacionales de comunicación”. García, D. (2008, p. 127), precisa que el prelado "consideraba que a la pobreza había que combatirla con educación y para llegar a los indígenas que se encontraban entre los páramos del Chimborazo, nada mejor que una radio".

\section{Prensa y catolicismo}

El nexo de Leonidas Proaño con lo periodístico puede evidenciarse en los medios que fundó, en la orientación que utilizó para difundir su presencia en el campo y en la ciudad, en la metodología utilizada para analizar la realidad e intervenirla, y en la integración de los indígenas a la vida del país.

Son aún incipientes los estudios que desde la academia se han realizado a los medios fundados por Leonidas Proaño y a los aportes que en el ejercicio periodístico ha realizado; sin embargo, este trabajo de investigación visibiliza lo que por años ha estado en el olvido de la opinión pública. Sus aportes pueden categorizarse como significativos dentro del periodismo con enfoque hacia la transformación social. Su posición contrahegemónica provocó tropiezos en la lucha por la reivindicación de los derechos colectivos. Su forma de comunicación construyó ciudadanía y formó personas dispuestas a convertir en actores del progreso.

Diego Cortes (2016, p. 103) sugiere la necesidad de plantear estrategias de comunicación que ayuden a construir y difundir propuestas de país diferentes a las establecidas. "Progresivamente las organizaciones de base han tenido que establecer sus 
propios medios de comunicación para la difusión y la creación de redes". Desde los sectores críticos de la comunicación de América Latina destacan que la obra en este campo, realizada por Proaño, y la señalan como una acción orientada hacia el cambio social que debe replicarse en los espacios formales e informales de educación. Tufte (2011) considera que:

"La comunicación para el cambio social es tanto un campo de práctica comunicativa como una disciplina académica de unos 50 a 60 años de antigüedad, a la cual muchos activistas y académicos latinoamericanos han hecho contribuciones clave. El campo se insiere en el campo internacional de la comunicación para el desarrollo, al recordar que la línea desarrollista y funcionalista dentro de este campo siempre ha sido contestado y rechazado por muchos en América Latina", (p. 66).

Para que los resultados expresados en la investigación guarden correspondencia con lo que Thomas Tufte señala en la referencia planteada en el párrafo anterior, debe precisarse que es uno de los activistas que, en América Latina, desde su praxis aportó a la comunicación y al periodismo que, luego fueron teorizados por académicos que pertenecen a la Escuela Latinoamericana de Comunicación.

\section{Metodología y muestra}

El presente trabajao de investigación es de tipo mixto: (cualitativo y cuantitativo); cualitativo, que desde la perspectiva de (Monje, 2011) permite la comprensión y al sentido, las razones, y las creencias que tienen las personas frente a su realidad, y, cuantitativo porque utiliza la estadística para observar, analizar e interpretar los resultados, (Gómez, Deslauriers y Piedrahita, 1990).

Se definió como muestra 225 ediciones-emisiones que fueron publicadosemitidos, durante 50 años, en nueve medios de comunicación masivos fundados (prensa y radio) por Leonidas Proaño, durante dos etapas: como seminarista y sacerdote (19341954) en Quito e Ibarra; y, como Obispo de Riobamba (1954-1984). En ellos se desempeñó como director y periodista. Para la preparación de los productos periodísticos tuvo como insumo la información recogida en los encuentros de capacitación, visitas comunitarias, audiencias en su despacho.

Como técnicas se emplearon la revisión documental como labor en la que el intelecto de investigar es utilizado para la interpretación y análisis que arrojará como resultado un producto para 1ser difundido. "Debe considerarse exclusivamente como descripción del contenido y no como descripción formal”, (Clauso, 1993, p. 11). Y, análisis de contenido, como instrumento aplicado a lo que se denomina discursos (contenidos y continentes), (Bardin,1986, p. 7). López (2002) precisa que este método sirve para estudiar y analizar las comunicaciones de una forma sistemátic y objetiva.

Los medios de comunicación en los que se difundieron las propuestas periodísticas de Proaño se detallan en la Tabla 1.

Tabla 1: Medios de comunicación fundados por Leonidas Proaño 


\begin{tabular}{c|c|c}
\hline TIPO/MEDIO & NOMBRE & AÑO DE PUBLICACIÓN \\
\hline Impreso & Periódico Excélsior & 1934 \\
\hline Impreso & Periódico Granitos de Trigo & 1938 \\
\hline Impreso & Periódico El Cuadrilátero & 1942 \\
\hline Impreso & Bisemanario La Verdad & 1944 \\
\hline Impreso & Revista Mensaje & 1955 \\
\hline Radio & Escuelas Radiofónicas Populares del Ecuador & 1962 \\
\hline Impreso & Periódico Jatari Campesino & 1965 \\
\hline Impreso & Periódico Jatari & 1971 \\
\hline Radio & Promoción & 1980 \\
\hline
\end{tabular}

Fuente: elaboración propia

El trabajo se desarrolló durante cinco etapas: a) En el Centro Documental de la Diócesis de Riobamba, y en la biblioteca Aurelio Espinoza Polit de Quito, sitios en los que reposan las 175 ediciones de Excélsior, Granitos de Trigo, El Cuadrilátero, La Verdad, Mensaje, Jatari Campesino y Jatari; y, los 50 guiones de los programas difundidos por ERPE y radio Promoción. b) Recuperación: utilizando la matriz de análisis que pertenece función preparatoria que según Galdón (2002, p. 70) entregar al investigador la información de útil para su trabajao c) La jerarquización (función críticoverificadora), que permite comprobar la exactitud de los hechos y compararlos con otras fuentes, clasificarlos por el nivel de importancia y de significación, que para Bravo (2011) es establecer el nivel de confiabilidad de la información. d) Selección y valoración, para Galdón es la función completiva que permite contextualizar los hallazgos, y clasificarlos en orden de importancia. f) Discusión y presentación comparando fundamentación con resultados.

Para la recuperación el diseño del instrumento contó con una columna que precisó el nivel semántico o ¿qué dice?; una segunda, que sirvió para identificar las; categorías discursivas; y en una tercera, el nivel pragmático o ¿cómo lo dice? Los tres elementos identificaron de qué forma los contenidos respondían al posicionamiento de los medios y a la intencionalidad que tenían para que los indígenas alcanzaran el cambio social.

\section{Resultados}

Los datos que contienen las tablas: (Orientación de los medios fundados por Proaño (1934-1984); Clasificación de contenidos presentados en los medios; Actos comunicativos como instrumento para la elaboración de contenidos), fueron recogidos mediante la utilización de las matrices diseñadas para la revisión documental y el análisis de contenido. La primera, condensa la información general. La segunda, presenta los géneros y formatos utilizados para difundir los hechos ocurridos en las comunidades indígenas y en los sectores suburbanos de Chimborazo; y) La tercera, los escenarios (actos de comunicación) en los que el Obispo de Riobamba se desenvolvió dentro de sus tareas de evangelización, educación e interacción con lo social. 
Tabla 2. Orientación de los medios fundados por Proaño (1934-1984)

\begin{tabular}{c|c|c}
\hline MEDIO & ETAPA DE PROAÑO & ORIENTACIÓN DEL MEDIO \\
\hline 1. Excélsior & Seminarista & Religiosa \\
\hline 2. Granitos de Trigo & Sacerdote & Religiosa, educativa \\
\hline 3. El Cuadrilátero & Sacerdote & Religiosa, social, sindical \\
\hline 4. La Verdad & Sacerdote & Religiosa, educativa, política, social \\
\hline 5. Mensaje & Obispo de Riobamba & Religiosa, educativa, política, social \\
\hline 6. ERPE & Obispo de Riobamba & Educativa, política, social \\
\hline 7. Jatari Campesino & Obispo de Riobamba & Educativa, política, social \\
\hline 8. Jatari & Obispo de Riobamba & Acción y desarrollo \\
\hline 9. Promoción & Obispo de Riobamba &
\end{tabular}

Fuente: elaboración propia

La Tabla 2 detalla en orden cronológico los medios de comunicación fundados por el Obispo de Riobamba, el tipo y el posicionamiento empleado para difundir las actividades desarrolladas en las visitas pastorales, en la recepción de campesinos, indígenas e indios en su oficina en el Palacio Episcopal, los encuentros con la gente en los barrios o en los sectores rurales de Chimborazo, entre otros. Y considera las etapas de vida del religioso entre el seminario en Quito, el ejercicio sacerdotal en Ibarra y la labor obispal en Riobamba. que fueron 50 años.

Tabla 3. Clasificación de los contenidos presentados en los medios

\begin{tabular}{|c|c|c|}
\hline MEDIOS & GÉNEROS & No. \\
\hline Excélsior & 10. Artículos & 8 \\
\hline \multirow[t]{2}{*}{ Granitos de Trigo } & 11. Editoriales & 25 \\
\hline & 12.Notas informativas & 12 \\
\hline El Cuadrilátero & 13. Artículos & 7 \\
\hline \multirow[t]{4}{*}{ La Verdad } & 14. Editoriales & 25 \\
\hline & 15. Notas informativas & 10 \\
\hline & 16. Relatos & 4 \\
\hline & 17. Humor & 6 \\
\hline \multirow[t]{4}{*}{ Mensaje } & 18. Editoriales & 25 \\
\hline & 19. Notas informativas & 22 \\
\hline & 20. Crónicas & 25 \\
\hline & 21. Humor & 7 \\
\hline \multirow[t]{2}{*}{$E R P E$} & 22. Comentarios & 25 \\
\hline & 23. Radiorevistas & 25 \\
\hline \multirow[t]{3}{*}{ Jatari Campesino } & 24. Editoriales & 25 \\
\hline & 25. Notas informativas & 11 \\
\hline & 26. Humor & 3 \\
\hline \multirow[t]{3}{*}{ Jatari } & 27. Editoriales & 25 \\
\hline & 28. Notas informativas & 17 \\
\hline & 29. Humor & 9 \\
\hline \multirow[t]{2}{*}{ Promoción } & 30. Comentarios & 25 \\
\hline & 31. Radiorevistas & 25 \\
\hline \multicolumn{2}{|c|}{ Total } & 366 \\
\hline
\end{tabular}

Fuente: elaboración propia 
Los contenidos que se observan en la Tabla 3 fueron elaborados por Proaño, con lo que se demuestra, que no solo se encargó de crear impresos o radios, sino que trabajó en ellos como periodista. Su estilo fue directo, manejó la geopolítica, tenía una impecable redacción, utilizaba la documentación informativa para sustentar las publicaciones considera Bravo, Galindo y Bravo (2019). Se observaron 366 apuestas periodísticas y el uso de nueve géneros y formatos de opinión e información; con ellos contó la realidad social de los pueblos oprimidos y emitió su criterio sobre las afectaciones causadas por la desatención y explotación, especialmente de los pobres, usando sus nueve medios (cinco periódicos y dos radios).

\section{Gráfico 1. Representación gráfica de los géneros de Proaño}

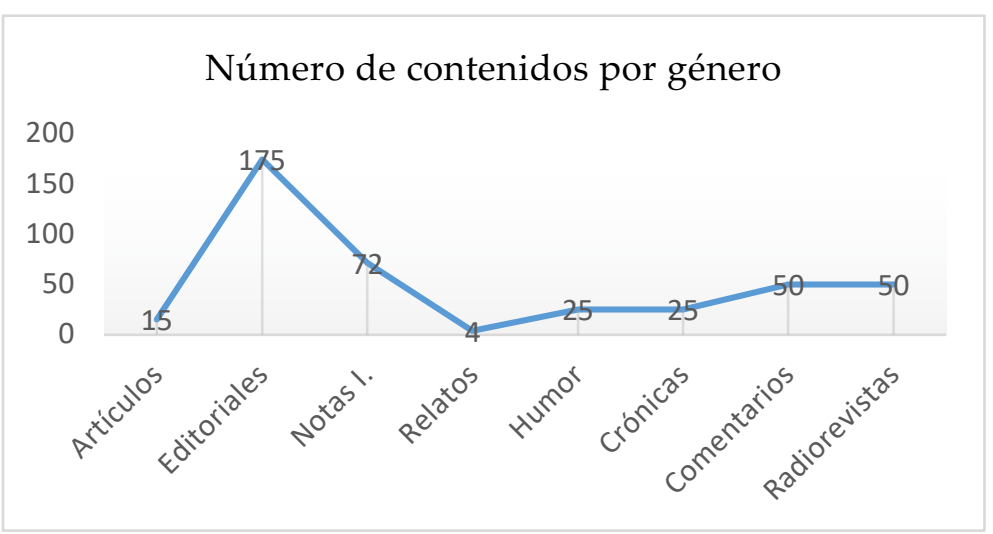

Fuente. Elaboración propia

La información representada en el Gráfico 1, corresponde a la sumatoria de los géneros por medio. En la Tabla 3, se presentan de forma individual los contenidos y esto no permite evidenciar la importancia de la producción periodística de Leonidas Proaño y la difusión de los hechos que apuntaron al cambio social.

Tabla 4. Actos comunicativos como instrumentos para la elaboración de contenidos

\begin{tabular}{|c|c|}
\hline ESCUCHA & $\begin{array}{l}\text { a) Visitas pastorales; b) Recorridos por comunidades; c) Audiencias; d) } \\
\text { Presencia en los barrios }\end{array}$ \\
\hline DIÁLOGO & $\begin{array}{l}\text { e) Encuentros de reflexión; f). Reuniones de pastoral indígena; g) } \\
\text { sesiones comunitarias; h) mingas; homilías; i) acercamientos con mujeres, } \\
\text { obreros, jóvenes, indígenas; k) mesas redondas; 1) conferencias; m). } \\
\text { seminarios. }\end{array}$ \\
\hline DIFUSIÓN & $\begin{array}{l}\text { n) Excélsior 8; Granitos de Trigo 37; El Cuadrilátero 7; La Verdad 45; } \\
\text { Mensaje 79; ERPE 50; Jatari Campesino 39; Jatari 51; radio Promoción } \\
\text { 50; o) Proaño, publicaba y leía cartas con respuestas de indígenas las } \\
\text { preguntas formuladas y difundía temas de relevancia (1970-1981).), p) } \\
\text { procesos de evangelización y alfabetización por radio; q )Escribió } \\
\text { editoriales en el periódico Jatari Campesino; r) Concedió entrevistas a } \\
\text { medios locales y nacionales; s) Entregó su posición frente a la situación } \\
\text { de los indígenas a mitad del siglo anterior.; t) incorporación del indio a la } \\
\text { vida civilizada. }\end{array}$ \\
\hline
\end{tabular}

Fuente: elaboración propia 
Los actos comunicativos que se reflejan en la Tabla 4 vinculan lo humano, biológico y tecnológico, desde la perspectiva de Martin Serrano y se evidencian en tres momentos: la escucha y el diálogo son el punto de partida para la acumulación de la información y publicación-emisión de 366 contenidos observados en los medios. Es necesario indicar que, para cada acto, Leonidas Proaño utilizó con prolijidad una metodología específica (ver-juzgar-actuar; teología de los signos de los tiempos; investigación acción comunicativa; teoría de la acción comunicativa).

\section{Discusión}

\section{Orientación de los medios de Proaño}

Significa el posicionamiento político, religioso, educativo, cultural o deportivo que asume un medio de comunicación y, a partir de él cuenta las historias (Bravo, 2012); responde a la línea editorial que es de aplicación obligatoria para los integrantes de la sala de redacción. Los contenidos difundidos en los cinco periódicos o en las dos radios de Proaño abordaron los temas desde siete ejes (religión, educación, política, social, sindical, acción y desarrollo) según describen los numerales 1 al 9 de la Tabla 2; corresponden también a tres momentos: seminarista, sacerdote y Prelado de Riobamba. Por ejemplo, el periódico Excélsior creado durante su permanencia como seminarista difundió temas relacionados con el evangelio, no obstante, empezaron a abordase aspectos vinculados con las teorías modernistas que estaban marcando la vida eclesial en Europa y que generaron discusión y confrontación con los religiosos conservadores, este hecho provocó el cierre del impreso tras dos años de circulación. El género periodístico que prevaleció fue el artículo que coincide con el numeral 10 de la Tabla 3, y con el literal (n, fase de difusión de la Tabla 4.

Para efectos de la presente investigación, se observó el posicionamiento de otro medio ( $\mathrm{La}$ Verdad) debido a las circunstancias que lo rodearon ya que en él identificó por primera vez su militancia por la solución de los problemas que afrontaban los indicios ecuatorianos. En 1944, tras la revolución populista del 28 de mayo en Guayaquil y la llegada a la presidencia de Ecuador de José María Velasco Ibarra, se conformó una asamblea con el fin de hacer cambios constitucionales, en los que Proaño pidió considerar a los indígenas en las decisiones que se adopten. El impreso corresponde al numeral 4 de la Tabla 2, en su misión sacerdotal; los contenidos se orientaban desde la religión, educación, política y social. Se encuentra en concordancia con los numerales 14 y 15 de la Tabla 3 que identifican el número de publicaciones por género empleado; y, también con los literales (n) y (s) de la Tabla 4, en este último se observa la participación en temas relacionados con la realidad social de los indígenas que eran la mayoría para mitad de siglo XX.

Cuando fue nombrado obispo, en 1954 organizó la Visita Pastoral con la que obtuvo información para publicarla en la revista Mensaje como consta en la Tabla 4, literal (a) que es parte de las actividades de escucha; Las historias que relató se condensan en los numerales 18 y 20 de la Tabla 3 . De la misma manera como consta en el punto 5 
de la Tabla 2, la orientación del medio respondía a los ejes religioso y educativo, y mantiene concordancia con el literal $(\mathrm{t})$ de la Tabla 4, componente de difusión a través del medio masivo en el que refiere la elaboración de su proyecto para que los indígenas y campesino den un giro en su vida y se aproximen a la civilización. Los procesos de evangelización y de alfabetización fueron dos aspectos en los que se puso énfasis para el cambio social.

\section{Clasificación de los contenidos presentados en los medios}

como se mencionó en párrafos anteriores, la producción 366 contenidos, es evidente en la utilización de cinco géneros periodísticos (artículos, editoriales, notas informativas, crónicas y humor) y dos formatos radiofónicos (comentarios $\mathrm{y}$ radiorevistas), recogidos en la Tabla 3. Es necesario citar algunos ejemplos para que permitan una mejor comprensión.

En la Tabla 4, el literal (b) relata la presencia del religioso en las comunidades; escuchó a los pobres su situación de esclavitud y opresión; gracias a este acto tuvo la información para difundir editoriales, crónicas, comentarios y radiorevistas (Tabla 3, numerales 18, 20, 22, 23, 30 y 31). Los contenidos se orientaron desde la mirada: religiosa, educativa, politica, social, acción y desarrollo, Tabla 2, numerales 5, 6 y 9).

Con ERPE (1962) y con Jatari Campesino (1965) Leonidas Proaño cumplió su propósito de que los indígenas aprendieran a leer y a escribir. La referencia de la emisión de la radio y del sexto medio impreso está recogida en la Tabla 2, numerales 6 y 7, los dos orientaron la información y la opinión desde la perspectiva religiosa, educativa, politica y social. Puso mayor énfasis en la propagación de la fe y en la alfabetización (Tabla 4, literal (p), fase de difusión). La producción periodística está registrada en la Tabla 3, numerales 22, 23 y 24. Es necesario distinguir que en el medio impreso prevaleció lo laico.

La proximidad que marcó con personas de toda condición social lograron distinguirle como un buen interlocutor e intermediador entre la gente y sus requerimientos. La fase de diálogo, Tabla 4, literales (h) y (l) evidenciaron que las conversaciones se desarrollaron en dos escenarios: no formales y formales. La minga, pertenece al primero por ser una actividad comunitaria para la cosecha, el arreglo de caminos, adecentamiento de espacios públicos, construcción de sistemas de alcantarillado o edificación de escuelas; en ella, mientras trabajaban conversaban los problemas y las necesidades, y se llegaban a soluciones, pero privilegiando la participación; primaba la participación colectiva. Y, las conferencias al segundo, porque estaban destinadas a auditorios diferentes en universidades, instituciones del sector público o en sindicatos.

La conformación de la pastoral indígena fue uno de los objetivos que Don Leonidas consiguió al final de su obispado, cuando ya estuvo de retirada, pero, tardó tres décadas, entre debates, procesos de mentalización, toma de conciencia y cambio de actitud sobre la necesidad de la presencia de sacerdotes nativos para fortalecer los espacios de evangelización. Esta acción, en concreto, consta en la Tabla 4, literales (b y 
f), fases de escucha y diálogo. El acercamiento con los campesinos le permitió contar con los elementos para construir el proyecto del cual empezó a hablar desde los primemos años como Obispo de Riobamba; se registró en la Tabla 3, numerales 18, 19 y 20; y respondió a la orientación religiosa (Tabla 2, numeral 5).

\section{Actos comunicativos como instrumentos para la elaboración de contenidos}

los resultados que arrojó la presente investigación evidenciaron tres espacios en los que Leonidas Proaño se desenvolvió, con el objetivo de: reflexionar sobre la realidad, diseño de estrategias de estrategias para transformarla, y finalmente, modificarla que equivalía a mejores condiciones de la gente pobre. Además, la información obtenida sirvió para construir contenidos: Los actos comunicativos son escucha, diálogo y difusión; están ubicados en la Tabla 4. Estos momentos formaron parte del trabajo metodológico desarrollado con fines de transformación. En las audiencias que constan en el literal (c) recibía un promedio de 50 personas cada sábado. Al despacho ubicado en el Palacio Episcopal llegaban indígenas, mestizos, jóvenes, niños, religiosos, monjas, autoridades y trabajadores; en la escucha, el obispo ponía atención a los criterios que la gente tenía sobre su vida y cómo hacer para mejorarla

Otro de los actos comunicativos que Proaño desarrolló fue el diálogo para solucionar los problemas y motivar la toma de conciencia de que el cambio social sí era posible, pero, éste debía empezar por el individuo y luego llegar a lo colectivo. Está presente en el literal (i) por los acercamientos realizados con mujeres, obreros, jóvenes, y principalmente indígenas. En la Tabla 3, numeral 20 consta la difusión realizada, a propósito de la visita a la fábrica La Cerámica y la conversación con el gerente y los trabajadores de la que surgió el centro cultural y de capacitación.

El liderazgo de Leonidas Proaño, a partir de su lucha por la reivindicación de los indígenas ecuatorianos tuvo eco en los medios nacionales que destacaron la obra desarrollada y los tropiezos que surgieron., como, por ejemplo, las denuncias en su contra que motivaron la visita de un delegado del Vaticano para abrir una investigación. La Tabla 4, liberal (r) refiere a su presencia en los diarios a través de las entrevistas publicadas en las que expresa su punto de vista frente al cambio. Este punto concuerda con el numeral 23, de la Tabla 3.

Como se pudo observar, la orientación de los medios fundados por Proaño, el tratamiento de los contenidos y los actos comunicativos se inter-relacionan unos con otros y entregan pertinencia al presente estudio.

\section{Conclusiones}

Sobre la base de la discusión de los resultados de los 366 contenidos elaborados por Leonidas Proaño (1934-1984) y su difusión en nueve medios masivos (prensa y radio), se llegaron a las siguientes conclusiones: 
Los resultados alcanzados respondieron la pregunta de investigación ¿Cuál fue la orientación de los medios fundados por Proaño y el reflejo en la difusión de la realidad socio-cultural y la actitud de cambio social de las comunidades indígenas de Ecuador entre 1934 y 1984? Los datos consignados en la Tabla 2, establecen la orientación que tuvieron los medios fundados por el Obispo de Riobamba, durante 50 años; al comienzo (Excélsior) se guardó una perspectiva religiosa, comprensible, porque ese encontraba en la fase de formación en el Seminario Mayor de Quito; pero conforme avanzaban los años se incorporó la educativa, sindical, política y social (Granitos de Trigo, El Cuadrilátero, La Verdad), ya en el ejercicio del sacerdocio. En su madurez, nombrado prelado, en 1954, mantuvo la orientación anterior en los otros Mensaje, ERPE, Jatari Campesino y Jatari, sin embargo, incorporó la acción y el desarrollo (radio Promoción) cuando empezó a preocuparse por la asociatividad de los indígenas y el impulso productivo para mejorar la calidad de vida. Queda demostrado que Don Leonidas, no solo dirigió su trabajo en los media, únicamente desde la religión o la educación, sino que desde otras miradas ejerció su actividad periodística.

Se confirmó el objetivo: Identificar el posicionamiento de los medios, la difusión de la pobreza del indio y la búsqueda de la transformación; La utilización de los géneros $\mathrm{u}$ formatos periodísticos que se esboza en la Tabla 3 sirvió para contar historias sobre los actos de escucha y diálogo que constan en la Tabla 4. Debe quedar claro que las apuestas periodísticas de Proaño buscaron el cambio social integral de las personas, pero no desde las individualidades sino de lo colectivo, otra de las luchas que libró y que originaron la conformación de organizaciones sociales como la Ecuarunari y la Conaie, Y, derivaron en los levantamientos indígenas para reivindicar su vida de esclavitud. Se debe insistir en que, las formas utilizadas para contar las historias propendían a la toma de conciencia y al cambio de actitud, como dos aspectos relevantes frente a la opresión.

Puede advertirse que en cada una de las tres etapas de la vida: de Leonidas Proaño seminarista, sacerdote y obispo, con la orientación de los medios fortaleció los procesos de evangelización y alfabetización, pero también, se preocupó de que los habitantes de las comunidades indígenas y de los sectores urbano-marginales, que estaban sumergidos en situación de extrema pobreza y de abandono, reflexionaran desde lo político, social, sindical, acción y desarrollo, que sí era posible alcanzar un nuevo estatus..

Los actos comunicativos de las tres etapas: escucha, diálogo y difusión (Tabla 4) aportaron información suficiente sobre la realidad que debía ser transformada y determinó que la proximidad con la gente no solo ejerció desde los eventos eucarísticos sino en otros escenarios. 


\section{Referencias}

Alcantara, L.C.S, Sampaio, C.A.C. \& Uriarte, L. (2018): "Experiencia Cooperativa de Mondragón: la educación cooperativa como un proceso de transformación social”, CIRIEC-España, Revista de Economía Pública, Social y Cooperativa, 93, 181-209, DOI: 10.7203/CIRIEC-E.93.9217. Fecha de consulta: 26-09-2018.

Alfaro, R. (1993). Una comunicación para otro desarrollo, Fundación Calandria. Lima.

Ávalos, B. (2017). Comunicación contrahegemónica, ventriloquía y lenguaje de contienda en Escuelas Radiofónicas Populares del Ecuador y Movimiento Indígena de Chimborazo 1960- $1990 . \quad$ (Tesis Recuperado de http://repositorio.flacsoandes.edu.ec/xmlui/bitstream/handle/10469/12441/TFLACSO2017MBAT.pdf? sequence=2\&isAllowed=y).

Bacher, C. (2016). Aportes de la investigación-acción participativa a una teología de los signos de los tiempos en América Latina. Theologica Xaveriana. Vol. 67 no. 184. jul.-dic. 2017. 309-332. Bogotá, Colombia. Issn 2011-219X.

Bardin, L. (1986): El análisis de contenido. Madrid, Akal

Baudrillard, J. (1984). Cultura y simulacro. Kairós. Barcelona

Berelson, B. (1952): Content Analysis in Communication Researches. Glencoe III, Free Press.

Canaval, G. (2000). El cambio social: análisis del concepto y aplicación en la investigación, educación y práctica de los profesionales de la salud. Colombia Médica, 31 (1), 37-42.

Castillo, M. T., Viga M. D., \& Dickinson (2008). Changing the culture of dependency to allow for succesful outcomein participatory research: Fourteen years in experience in Yucatán, México. En P. Reason y H. Bradbury (eds.). The sage handbooks of action research, participatory inquiryand practice (pp. 522-523). Los Ángeles Sage.

Clauso, A. (1993). P uisía General dc Inflirinacián y Dtx,nnenta i6n, Vol. 3 (II, 11-19, Edil. Complutense. Madrid.

Corredor-Aristizábal, J. (2010). Revista Colombiana de Psicología. Vol. 19 n. ${ }^{\circ} 2$ juliodiciembre 2010. issn 0121-5469. Bogotá, Colombia.

Cortes, D. (2016). Representación indígena en el periodismo colombiano. Jangwa Pana, $15(1), 88-104$.

Dubravcic, M. (2002). Comunicación Popular. Ediciones Abya Yala. Quito - Ecuador

Freire, Paulo. 1976. Pedagogía del Oprimido. México: Siglo XXI Editores

García, D. (2008). Por los caminos de la Educación Radiofónica. Universidad de Brasil 
Gavilanes, J. (1992). Monseñor Leonidas Proaño y su misión profético-liberadora en la iglesia de América Latina. FEPP. Quito - Ecuador.

Gómez, M,; Deslauriers , J.; y Piedrahita, M. (2010). Cómo hacer tesis de maestría y doctorado - investigación, escritura y publicación. Ecoe Ediciones. Bogotá

Gramsci, A. (1970). Introducción a la filosofía de la praxis. Barcelona: Península

Guardiola, E. (2017). Convergencias de la investigación acción participativa y el pensamiento complejo. Investigación \& desarrollo vol. 25, n ${ }^{\circ} 1$ (2017) - issn 2011-7574 (on line). Fecha de consulta: 24 de octubre de 2017.

Herrera M. Environmentalism and political participation: toward a new system of social beliefs and values. J Appl Social Psychol 1992; 22: 657-76.

Huergo, Jorge A., Nuevas aventuras de la perspectiva crítica: la investigación "con" la transformación social. Nómadas (Col) [en linea] 2002, (Sin mes) : [Fecha de consulta: 24 de octubre de 2018] Disponible en: $\leq$ http://www.redalyc.org/articulo.0a?id=105117951004> ISSN 0121-7550

Igartúa, J. \& Humanes, M. (2010). Teoría e Investigación en Comunicación Social. Editorial Síntesis. Madrid - España.

Kaplún, M. (1983). Comunicación popular ¿alternativa válida? Revista Chasqui Vol. 7. Quito - Ecuador.

Kemmis, R. \& Mc Taggart, R. (2005). Participatory Action Research. Comunicative action and the public sphere. En N. Denzin y. Lincoln (eds.). The sage handbooks of qualitative research (pp. 559-603). Londres: Sage.

Kirk, J. \& Miller, M. (1986), Reliabilitv !lild \ialidily in Qualitative Research, New Park: California: Sage, Qualitative Research Methods Series.

Kvale, S. (1961). Imerviews. AII trodllc to qllalitalive research tervieving, Londres: Sage.

López, F. (2002): El análisis de contenido como método de investigación. Revista de Educación, 4 (2002): 167-179. Universidad de Huelva.

Máiz, R. (2004). Revista de Estudios Políticos (Nueva Época) Núm. 123. Enero-marzo 2004. México.

Marcuse, H. Über konkrete Philosophie. Frankfurt am Main, Europäische Verlagsanstalt, 1973. Y en: "Schriften". Vers. cit. 1987. Un análisis bastante interesante en: Spiro, L.: "The Freudo-Marxism of Herbert Marcuse". Columbia University Press, 1973.

Mills, C. W. (1959), The sociological imagination, Nueva York: The Oxford University Press. 
Monje, C. (2011). Metodología de la investigación cualitativa y cuantitativa. Universidad SurColombiana. Neiva.

Muñoz, M. (2011). A propósito de La Dialéctica Concreta de Herbert Marcuse. Universidad Carlos III de Madrid, Madrid, España.

ONU (1954). El Desarrollo Económico del Ecuador. Estudio realizado por la Secretaría de la Comisión Económica para América Latina - CEPAL (Reedición). México.

Ossandon, F (1988). Comunicación popular, alternativa y participatoria. Ediciones Ciespal. Quito - Ecuador.

Park, P. (2011). Qué es la investigación acción participativa. Perspectivas teóricas y metodológicas. En La investigación acción participativa. Inicios y desarrollos, Editado por María Cristiana Salazar, 135-174. Bogotá: Magisterio.

Pellegrino, L. (2017). Las historias de vida en el método de planificación pastoral verjuzgar-actuar. Veritas, № 36 (Abril 2017). Italia.

Proaño, L. (1956). De conversación con mis hijos - la parcelación. Revista Mensaje (Diócesis de Riobamba). p. 8.

Proaño, L. (1959). De conversación con mis hijos - Horizontes. Revista Mensaje (Diócesis de Riobamba). pp.176-178.

Proaño, L. (1960). De conversación con mis hijos - El CEAS. Revista Mensaje (Diócesis de Riobamba). pp. 81-82.

Proaño, L. (1974). Concientización, evangelización y política. Ediciones Sígueme. Salamanca - España.

Proaño, L. (1976). Evangelio Subversivo. Ediciones Sígueme. Salamanca - España.

Proaño, L. (2011). Abriendo surcos indígenas 1. Fondo Documental Diocesano. Riobamba, Ecuador.

Proaño, L. (2011). Abriendo surcos indígenas 1. Fondo Documental Diocesano. Riobamba, Ecuador.

Proaño, L. (2011). Creo en el hombre y en la comunidad. Studio 21. Quito, Ecuador.

Rizo García, Marta, Comunicación e interacción social. Aportes de la comunicología al estudio de la ciudad, la identidad y la inmigración. Global Media Journal [en linea] 2004, 1 (otoño): [Fecha de consulta: 23 de julio de 2018] Disponible en: $\leq$ http://www.redalyc.org/articulo.0a?id=68710210 $>$ ISSN 2007-2031

Rizo, M. (2012). Imaginarios sobre la comunicación. Algunas certezas y muchas incertidumbres en torno a los estudios de comunicación, hoy. Bellaterra: Institut 
de la Comunicació, Universitat Autònoma de Barcelona. ISBN 978-84-9396746-8

Rojas, R. (2012). Investigación - acción - participativa. Universidad Politécnica Salesiana.

Saldívar, E. (2003). Indigenismo Legal: la política indigenista de los noventas. Revista Mexicana de Ciencias Politicas y Sociales, XLVI (189), 311-339.

Sanz, F. (2001). La Juventud Obrera Cristiana: Un movimiento educativo popular. Ediciones Universidad de Salamanca. Hist, educ. y 20, 2001, pp. 95-115. Fecha de consulta: 24-09-2018

Selener, D. (1997). Participatory action research and social change. NY: Cornell University Participatory Action Research Network. Fecha de consulta: 24-092018

Serrano, M. (1982). Teoría de la Comunicación. Gráficas Valencia. Madrid - España

Silva, E. (2009). Una teología de los signos de los tiempos latinoamericanos. Validez, límites y porvenir de una hermenéutica teológica del Concilio. Teología y Vida, L (1-2), 41-58.

Singer, M. (2011). ¿Exclusión o inclusión indígena? Universidad Nacional Autónoma de México, Facultad de Ciencias Políticas y Sociales, Centro de Estudios Políticos. Estudios Políticos núm. 31 (enero-abril, 2014): 87-106. México, D.F. ISSN: 01851616. Fecha de consulta: 24-09-2018

Stavenhagen, Rodolfo (2001), "El derecho de sobrevivencia: la lucha de los pueblos indígenas en América Latina contra el racismo y la discriminación", Santiago de Chile, Comisión Económica para América Latina y el Caribe, Instituto Interamericano de Derechos Humanos, Reunión de Expertas sobre Racismo y Género, 4 y 5 de junio. Fecha de consulta: 24-09-2018.

Tufte, T (2011). ¿Dónde están los medios públicos en América Latina? Signo y Pensamiento 58 · Eje Temático | pp 64-78 · volumen XXX · enero - junio 2011

Urdapilleta \& Llilmón (2018). Revista Colombiana de Sociología. Vol. 47 No. 1. Enero - junio 2018. Bogotá, Colombia.

Vélez, C. (2016). "El quehacer teológico y el método de investigación acción participativa. Una reflexión metodológica". Theologica Xaveriana 183 (2017):187-208. https://doi.org/10.11144/javeriana. tx67-183.qtmiap. Fecha de consulta: $25-09-2018$

Wals, A. (2007). Social learnig towards a sustainable world. Holanda: Wageningen Academics. 